\title{
Clinical Risk Factors for Poor Anatomic Response to Ranibizumab in Neovascular Age-Related Macular Degeneration
}

\author{
Josef Guber $^{*}, 1$, Tatjana Josifova ${ }^{2}$, Paul Bernhard Henrich ${ }^{2}$ and Ivo Guber ${ }^{3}$ \\ ${ }^{1}$ Sutton Eye Hospital, Epsom and St Helier University Hospitals, London, UK \\ ${ }^{2}$ Department of Ophthalmology, University of Basel, Basel, Switzerland \\ ${ }^{3}$ Eye Clinic, Cantonal Hospital of Winterthur, Winterthur, Switzerland
}

\begin{abstract}
Purpose: To identify OCT-based anatomical features and clinical characteristics for poor central retinal thickness (CRT) response to ranibizumab in neovascular age-related macular degeneration (AMD).

Patients and Methods: Investigating our electronic patient records (Eyeswide), patients with neovascular AMD treated with intravitreal injections of $0.5 \mathrm{mg} / 0.05 \mathrm{ml}$ ranibizumab were identified and their notes reviewed. Data collected included gender, age, initial best-corrected visual acuity (BCVA), prior photodynamic therapy, lesion type (classic versus occult), type of macular edema (intraretinal fluid, subretinal fluid, pigment epithelium detachment) and the total number of previous ranibizumab injections.

Results: A total of 210 eyes of 182 patients with neovascular AMD were identified. Mean follow-up time was 1.34 years $(\mathrm{SD} \pm 0.77)$. Central retinal thickness reduction in women was significantly inferior to that in men $(p=0.05)$. Patients with cystoid type macular edema had significantly greater reduction in CRT compared to patients with subretinal fluid $(p<0.001)$ or pigment epithelium detachment $(p<0.001)$. The percentage drop of CRT was no longer statistically significant after the sixth injection. Age, initial BCVA, prior photodynamic therapy and lesion type had no statistically effect on CRT response.

Conclusion: Risk factors for poor central retinal thickness response to ranibizumab include female gender and patients with predominant subretinal fluid or pigment epithelium detachment. Furthermore, the anatomical response decreased after the sixth injection of ranibizumab.
\end{abstract}

Keywords: Age-related macular degeneration, Lucentis, poor-responder, ranibizumab, risk factors.

\section{BACKGROUND}

Neovascular age-related macular degeneration (AMD) is a serious disorder of the central retina leading to rapid loss of central vision [1-3].

Ranibizumab (Lucentis ${ }^{\circledR}$, Novartis Pharma AG, Switzerland), a humanized monoclonal antibody fragment targeting multiple isoforms of human vascular endothelial growth factor (VEGF), has revolutionized the treatment for neovascular AMD [4]. The efficacy and safety of ranibizumab have been demonstrated in major clinical trials [5-8]. Ranibizumab's therapeutic effect appears maximal within the first three months of treatment and regular treatment once a month is associated with optimum visual acuity and anatomical response $[5,6]$. However, the PrONTO Study showed that the visual outcome was similar using a variable-dosing regimen [9].

*Address correspondence to this author at the Sutton Eye Hospital, Epsom and St Helier University Hospitals, NHS Trust, Cotswold Road, London, SM2 5NF, UK; Tel: +44 208296 2000; Fax: +44 208770 7051;

E-mail: josef.guber@esth.nhs.uk

${ }^{\S}$ Presented at the Annual Congress of the Royal College of Ophthalmologists, Liverpool, UK, May 2013.
Optical coherence tomography (OCT) is now regarded as the single most important tool in monitoring disease activity and treatment success. The decision for retreatment is generally based on OCT findings [10-12].

The aim of the present study was to identify clinical characteristics at presentation for poor central retinal thickness response to intravitreal injections of ranibizumab in wet AMD.

\section{PATIENTS AND METHODS}

\section{Patients}

Research adhered to the tenets of the Declaration of Helsinki.

Investigating our electronic patient records (Eyeswide), patients with neovascular AMD treated with intravitreal injections of $0.5 \mathrm{mg} / 0.05 \mathrm{ml}$ ranibizumab were identified and their notes reviewed. The evidence of choroidal neovascularization $(\mathrm{CNV})$ was confirmed by fluorescein angiography. Patients were treated with ranibizumab following the PrONTO regime [9]. After a loading dose of three injections, criteria for further anti-VEGF injections were; detection of any intraretinal, subretinal fluid, serous pigment epithelium detachment, haemorrhage or drop in 
vision. Patients were followed up monthly and by OCT regardless whether they received an injection or not until six months after the last injection. The patient's baseline characteristics are shown in Table $\mathbf{1}$.

Table 1. Patients characteristics at baseline.

\begin{tabular}{|c|c|c|}
\hline Characteristics & n=210 (Eyes) & $\%$ \\
\hline $\begin{array}{l}\text { Gender (n) } \\
\quad \text { Male } \\
\text { Female }\end{array}$ & $\begin{array}{l}64 \\
118\end{array}$ & $\begin{array}{l}35.2 \% \\
64.8 \%\end{array}$ \\
\hline $\begin{array}{l}\text { Age (y) } \\
\quad \text { Mean (SD) } \\
\text { Range } \\
50 \text { to } 75 \\
\geq 75\end{array}$ & $\begin{array}{l}83(9) \\
51-100 \\
28 \\
179\end{array}$ & $\begin{array}{l}13.5 \% \\
86.5 \%\end{array}$ \\
\hline $\begin{array}{c}\text { Eye (n) } \\
\text { Right } \\
\text { Left }\end{array}$ & $\begin{array}{l}100 \\
110\end{array}$ & $\begin{array}{l}47.6 \% \\
52.4 \%\end{array}$ \\
\hline $\begin{array}{l}\text { Lesion type (n) } \\
\text { Classic } \\
\text { Occult }\end{array}$ & $\begin{array}{l}69 \\
141\end{array}$ & $\begin{array}{l}32.9 \% \\
67.1 \%\end{array}$ \\
\hline $\begin{array}{l}\text { Macular edema type (n) } \\
\text { Intraretinal fluid } \\
\text { Spongoid type } \\
\text { Cystoid type } \\
\text { Subretinal fluid } \\
\text { PED }\end{array}$ & $\begin{array}{l}216 \\
124 \\
92 \\
190 \\
99\end{array}$ & $\begin{array}{l}42.8 \% \\
24.6 \% \\
18.2 \% \\
37.6 \% \\
19.6 \%\end{array}$ \\
\hline $\begin{array}{l}\text { Initial BCVA }(\log (\text { MAR })) \\
\text { Mean (SD) } \\
\text { Range } \\
\geq 0.4 \\
0.3 \text { to } 0.0\end{array}$ & $\begin{array}{l}0.6(0.4) \\
0.0-1.9 \\
141 \\
58\end{array}$ & $\begin{array}{l}70.9 \% \\
29.1 \%\end{array}$ \\
\hline Prior photodynamic therapy (n) & 26 & $12.4 \%$ \\
\hline $\begin{array}{l}\text { Follow up (y) } \\
\text { Mean (SD) } \\
\text { Range }\end{array}$ & $\begin{array}{l}1.34(0.77) \\
0.16-3.39\end{array}$ & \\
\hline $\begin{array}{l}\text { Injections (n) } \\
\text { Mean (SD) } \\
\text { Range }\end{array}$ & $\begin{array}{l}6(2.7) \\
2-14\end{array}$ & \\
\hline
\end{tabular}

OCT scans (Cirrus ${ }^{\mathrm{TM}}$ HD-OCT 400, Software 4.0, Carl Zeiss Meditec, Jena, Germany) of these patients' were reviewed by two trained observers. Macular edema was classified as either predominant intraretinal fluid (IRF), subretinal fluid (SRF) or as predominant pigment epithelium detachment (PED). In addition, intraretinal fluid was differentiated in cystoid type (cyst diameter $>150 \mathrm{um}$ ) and spongiod type (cyst diameter $<150 \mathrm{um}$ ).

\section{Statistics}

To describe mean relative change in central retinal thickness (CRT) compared to a reference central retinal thickness (RCRT) for several predictors, a multivariate analysis was performed. Subject was treated as random factor. Results were presented as mean percentage differences to RCRT with the corresponding $p$-values and $95 \%$ confidence intervals. All evaluations were done using $\mathrm{R}$ version 15.1 .

Reference central retinal thickness was defined for each eye as the mean foveal thickness of all examinations in which no intraretinal (IRF), subretinal fluid (SRF) or pigment epithelium detachment (PED) could be observed.

The factors analyzed were gender, age (50 to 74 versus $\geq 75$ years), initial best corrected visual acuity (BCVA; LogMAR $\geq 0.4$ versus 0.3 to 0.0 ), prior photodynamic therapy, lesion type (classic versus occult), type of macular edema and the total number of injections.

\section{RESULTS}

A total of 1141 injections in 210 eyes of 182 patients were performed. Mean number of injections per patient was 6 (range 2 - 14). Mean follow-up time was 1.34 years (range 0.16 - 3.39). Patients' characteristics at baseline were summarized in Table $\mathbf{1}$.

The multivariate analysis of the various clinical factors showed that the central retinal thickness reduction in women was significantly inferior to that in men $(-6.47 \%, 95 \% \mathrm{CI} \pm$ $6.56, p=0.05$ ). Age, initial BCVA and prior photodynamic therapy had no effect on macular thickness response.

Statistical evaluation of the macular edema types revealed that patients with predominant intraretinal fluid ( $\Delta$ to RCRT $35.72 \%, 95 \% \mathrm{CI} \pm 10.8$ ) responded better compared with patients with subretinal fluid ( $\Delta$ to RCRT $28.97 \%, 95 \% \mathrm{CI} \pm 9.34, p=0.001)$ or pigment epithelium detachment $(\Delta$ to RCRT $27.61 \%, 95 \%$ CI \pm 10.61 , $p=<0.001)$. Furthermore, subgroup analysis showed that patients with a cystoid type of macular edema ( $\Delta$ to RCRT $44.26 \%, 95 \% \mathrm{CI} \pm 10.76)$ had a significantly greater reduction of macular thickness compared to patients with spongiod type of macular edema ( $\Delta$ to RCRT $27.17 \%$, $95 \% \mathrm{CI} \pm 10.86, p=0.001)$. Lesion type had no effect on macular thickness response. An overview of the multivariate analysis is summarized in Table $\mathbf{2}$.

Regarding the total number of injections: after the first injection maximum response is evident ( $\Delta$ to RCRT $27.17 \%$, $95 \% \mathrm{CI} \pm 10.86, p=0.001)$; thereafter the reduction of CRT remains stable until injection 6 ( $\Delta$ to RCRT $18.42-12.16 \%$, $p<0.05)$. Further treatments did not lead to a statistically significant CRT reduction ( $\Delta$ to RCRT $<12 \%$; Fig. 1).

\section{DISCUSSION}

Analysis of risk factors is of paramount importance for the understanding of a disease and has a high impact on our daily clinical practice. Furthermore, considering the significant treatment costs in patients with wet AMD, it is important to identify predictive factors in order to evaluate cost effectiveness.

We identified several baseline characteristics associated with the risk for poor reduction of macular edema including female gender, macular edema with predominant subretinal fluid and patients with a predominant pigment epithelium detachment. In addition, we found that the maximal reduction of CRT had occurred by injection six. Thereafter ranibizumab had no longer the same good effect on the central retinal thickness. 


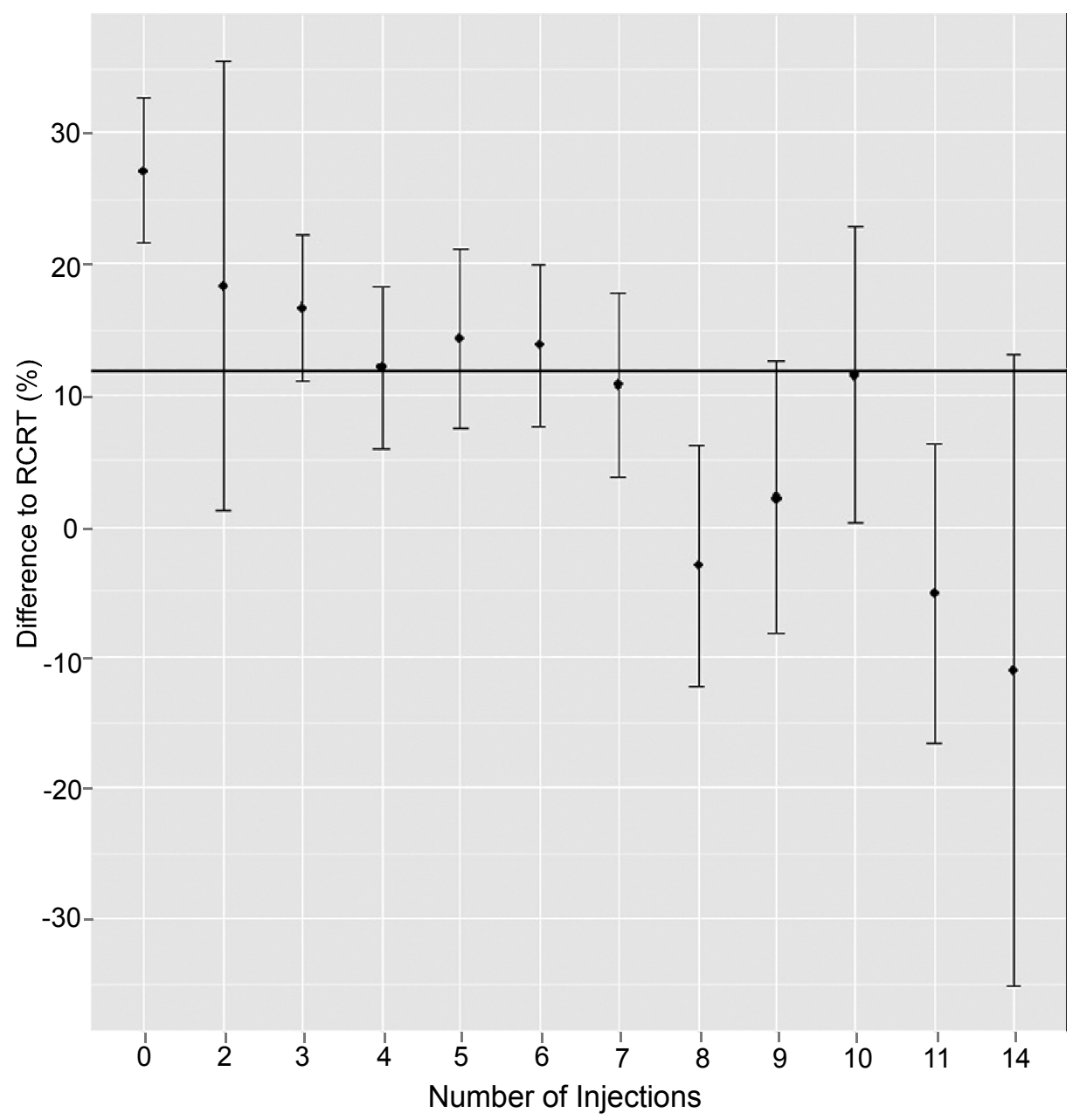

Fig. (1). Effect of ranibizumab on mean central retinal thickness in percentage by number of injection. The line marks the statistical significant response $(p=0.05)$. RCRT $=$ reference central retinal thickness.

Table 2. Multivariate analysis of predictive factors for central retinal thickness response to ranibizumab.

\begin{tabular}{|l|l|l|l|}
\hline \multicolumn{1}{|c|}{ Predictive Factors } & \multicolumn{1}{|c|}{$\%$} & $\mathbf{9 5 \%}$ CI & $\boldsymbol{p}$ Value \\
\hline \hline $\begin{array}{l}\text { Gender } \\
\text { women - men }\end{array}$ & -6.47 & \pm 6.56 & 0.05 \\
\hline $\begin{array}{l}\text { Age (y) } \\
\geq 75-<74\end{array}$ & 4.93 & \pm 8.79 & 0.27 \\
\hline $\begin{array}{l}\text { Initial BCVA (log(MAR)) } \\
\geq 0.4-<0.3\end{array}$ & -3.34 & \pm 7.18 & 0.36 \\
\hline $\begin{array}{l}\text { Prior photodynamic therapy } \\
\text { yes - no }\end{array}$ & 3.24 & \pm 8.9 & 0.48 \\
\hline Lesion type & & & \\
occult - classic & 1.24 & \pm 6.7 & 0.70 \\
\hline Macular edema type & & & \\
IRF $\downarrow$ to RCRT & 35.72 & \pm 10.8 & $<0.001$ \\
spongiod type IRF $\downarrow$ to RCRT & 44.26 & \pm 10.76 & $<0.001$ \\
cystoid type IRF $\downarrow$ to RCRT & 27.17 & \pm 10.86 & $<0.001$ \\
SRF $\downarrow$ to RCRT & 28.97 & \pm 9.34 & \\
PED $\downarrow$ to RCRT & 27.61 & \pm 10.61 & \\
\hline
\end{tabular}

IRF = intraretinal fluid, SRF = subretinal fluid, PED = pigment epithelium detachment, $\mathrm{RCRT}=$ reference central retinal thickness.
Different theories explain unrewarding therapeutic response to ranibizumab therapy. For instance, various reports describe resistance to anti-VEGF-A antibodies secondary to regulatory feedback loops: Schaal et al. introduced the concept of tachyphylaxis associated with repeated bevacizumab injections for neovascular AMD. They found that after approximately three injections of bevacizumab, the initial efficacy was decreased by $50 \%$ [13]. Another retrospective review found tachyphylaxis after five to ten injections of bevacizumab [14]. Similar to ANCHOR and MARINA studies, the response to treatment in our patient population was independent of baseline patient characteristics such as age, initial visual acuity and lesion type or prior photodynamic therapy $[5,6,15]$.

These findings indicate that neovascular AMD may feature more subtle subgroups than previously known but further research is needed to correlate our findings with genetic genotype polymorphism which were recently described [16]. However, we believe that our findings contribute to a better understanding of the prognosis of several subgroups in wet AMD and this should be taken in account and must be explained to the patient before treatment.

\section{CONFLICT OF INTEREST}

The authors confirm that this article content has no conflict of interest. 


\section{ACKNOWLEDGEMENTS}

Andreas Schötzau, dipl. math., Department of Biomedicine, University Hospital Basel: statistical analysis.

Muhammad Usman Saeed, Consultant Ophthalmologist, Sutton Eye Hospital: review of the manuscript.

\section{REFERENCES}

[1] Bressler NM. Age-related macular degeneration is the leading cause of blindness. JAMA 2004; 291:1900-1.

[2] Friedmann DS, O'Colmain BJ, Munoz B, et al. Prevalence of agerelated macular degeneration in the United States. Arch Ophthalmol 2004; 122: 564-72.

[3] Ferris FL $3^{\text {rd }}$, Fine SL, Hyman L. Age-related macular degeneration and blindness due to neovascular maculopathy. Arch Ophthalmol 1984; 102: 1640-42.

[4] Ferrara N, Damico L, Shams N, Lowman H, Kim R. Development of ranibizumab, an anti-vascular endothelial growth factor antigen binding fragment, as therapy for neovascular age-related macular degeneration. Retina 2006; 26: 859-70.

[5] Rosenfeld PJ, Brown DM, Heier JS, et al. Ranibizumab for neovascular age-related macular degeneration. N Engl J Med 2006; 355: 1419-31.

[6] Brown DM, Kaiser PK, Michels M, et al. Ranibizumab versus verteporfin for neovascular age-related macular degeneration. N Engl J Med 2006; 355: 1432-44.

[7] Regillo CD, Brown DM, Abraham P, et al. Randomized, doublemasked, sham-controlled trial of ranibizumab for neovascular agerelated macular degeneration: PIER Study year 1. Am J Ophthalmol 2008; 145: 239-48.

[8] Schmidt-Erfurth U, Eldem B, Guymer R, et al. Efficacy and safety of monthly versus quarterly ranibizumab treatment in neovascular age-related macular degeneration: the EXCITE Study. Ophthalmology 2011; 118: 831-9.

[9] Lalwani GA, Rosenfeld PJ, Fung AE, et al. A variable-dosing regimen with intravitreal ranibizumab for neovascular age-related macular degeneration: year 2 of the PrONTO Study. Am J Ophthalmol 2009; 148(1): 43-58.e1. doi: 10.1016/j.ajo.2009.01.024

[10] Fung AE, Lalwani GA, Rosenfeld PJ, et al. An optical coherence tomography-guided, variable dosing regimen with intravitreal ranibizumab (Lucentis) for neovascular age-related macular degeneration. Am J Ophthalmol 2007; 143: 566-83.

[11] Mitchell P, Korobelnik JF, Lanzetta P, et al. Ranibizumab (Lucentis) in neovascular age-related macular degeneration: evidence from clinical trials. Br J Ophthalmol 2010, 94(1): 2-13.

[12] Holz FG, Amoaku W, Donate J, et al. Safety and efficacy of a flexible dosing regimen of ranibizumab in neovascular age-related macular degeneration: the SUSTAIN Study. Ophthalmology 2011; 118: 663-71.

[13] Schaal S, Kaplan HJ, Tezel TH. Is there tachyphylaxis to intravitreal anti-vascular endothelial growth factor pharmacotherapy in age-related macular degeneration? Ophthalmology 2008; 15(12): 2199-205.

[14] Forooghian F, Cukras C, Meyerle CB, Chew EY, Wong WT Tachyphylaxis after intravitreal bevacizumab for exudative agerelated macular degeneration. Retina 2009; 29(6): 723-31.

[15] Boyer DS, Antoszyk AN, Awh CC, et al. Subgroup analysis of the MARINA Study of ranibizumab in neovascular age-related macular degeneration. Ophthalmology 2007; 114: 246-52.

[16] McKibbin M, Ali M, Bansal S, et al. CFH, VEGF and HTRA1 promoter genotype may influence the response to intravitreal ranibizumab therapy for neovascular age-related macular degeneration. Br J Ophthalmol 2012; 96(2): 208-12.

(C) Guber et al.; Licensee Bentham Open.

This is an open access article licensed under the terms of the Creative Commons Attribution Non-Commercial License (http://creativecommons.org/licenses/by-nc/3.0/) which permits unrestricted, non-commercial use, distribution and reproduction in any medium, provided the work is properly cited. 